\title{
Small intestinal microbiological and morphological observations in young calves fed milk replacers enriched with a combination of lactoperoxidase system and lactoferrin
}

\author{
P. van Leeuwen', J. Huisman', H. M. Kerkhof ${ }^{2}$ and K. Kussendrager ${ }^{3}$ \\ 'TNO Nutrition and Food Research, Department of Animal Nutrition and Physiology (ILOB) \\ P.O. Box 15, 6700 AA Wageningen, The Netherlands \\ ${ }^{2}$ Nutrifeed Veghel, The Netherlands \\ ${ }^{3}$ DMV International, Veghel, The Netherlands
}

\begin{abstract}
A study has been made of the effects of a combination of lactoperoxidase system (LP-s) and lactoferrin (LF), supplemented to milk replacer for 2 weeks, on the morphology of the small intestinal mucosa, microbiology of the intestinal tract and the incidence and severity of diarrhoea in young calves. The experiment was conducted in two groups of 15 young calves, aged 7 to 21 days. The results showed a lower incidence and severity of diarrhoea $(\mathrm{P}<0.05)$ in the calves of the LP-s/LF group compared to the control group. CFU (Colony forming units) of $E$. coli in colonic digesta $(\mathrm{P}=0.10)$ and in faeces $(\mathrm{P}<0.05)$ were significantly lower in the $\mathrm{L}-\mathrm{s} / \mathrm{LF}$ group compared to the control group. Dissecting microscopy of the small intestinal mucosa indicated more finger-shaped villi in the distal jejunum of the calves of the LP-s/LF group compared to the control group $(\mathrm{P}=0.01)$. Histometrical measurements showed that these villi were significantly $(\mathrm{P}=0.002)$ higher. The mean contents of immunoglobulins $(\lg G)$ increased $(\mathrm{P}=0.1)$ during the test period whereas those of the control group remained unchanged.
\end{abstract}

KEY WORDS: lactoperoxidase system, lactoferrin, calves

\section{INTRODUCTION}

A combination of two bioactive proteins, lactoperoxidase system (LP-s) and lactoferrin (LF), was added to a milk replacer. The chemical and biological properties of the LP-s have been reviewed by De Wit and Hooydonk (1996) and Reiter 
and Perraudin (1991) while the structure and functions of lactoferrin (LF) were reviewed by Lönnerdal and Iyer (1995).

The present study was carried out to investigate the effect of adding LP-s and LF to milk replacer on the incidence and severity of diarrhoea, the intestinal microbiology and the morphology of the small intestinal mucosa.

\section{MATERIAL AND METHODS}

Thirty Fresian-Dutch calves aged approximately 7-d were assigned to one of two treatment groups $(n=15)$ based on body weight. The calves were fed a commercial milk replacer diet without antibiotics. The animals of the test group (LP-s/LF) received the diet with a supplement of bovine LP-s/bovine LF concentrate. Bovine LP-s and bovine LF were supplied by DMV International, Veghel, The Netherlands. The milk replacer had a final concentration of $200 \mathrm{mg} / \mathrm{kg} \mathrm{LP}$ and $1000 \mathrm{mg} / \mathrm{kg}$ of bovine LF (20\% Fe saturated). The LP activity was $1000 \mathrm{U} / \mathrm{g}$ using the ABTS method (De Wit and van Hooydonk, 1996). The control group (C) received the same diet with placebo supplementation.

Both groups were fed twice a day according to a standard feeding schedule. During the experiment feed intake and faecal score, with 0 for normal faeces and 3 for severe diarrhoea, were recorded. The experiment was concluded on day 13 after arrival. Faccal samples were taken daily from the rectum of each animal from day 6 to day 10 for determination of bacterial counts. Three $h$ post-feeding blood samples were taken on days 2 and 13. Haematological parameters were determined in blood taken on day 13 , and $\operatorname{IgG}$ contents were determined in blood sera taken on days 2 and 13. On day 14 (one day after the end of the experiment) dissection was conducted at $0.5 \mathrm{~h}$ after feeding.

Haematological parameters, haemoglobin, erythrocyte counts, haematocrit and leucocyte counts were determined with a Symex F800 flowcytometer (Symec, Japan). The IgG content in blood plasma was determined turbidimetrically with a specific antibody against bovine IgG (Nordic, Tilburg, The Netherlands). The CFU (Colony forming units) of Escherichia coli (E. coli) in faces were determined according to IDF (1985), E. coli in digesta according to IDF (1997), LAB (lactic acid producing bacteria) in digesta according to FNZ (1986), and salmonellae according to ISO (1993) and NEN (1994).

The shape of the villi was studied with a dissecting microscope and characterized according to Mouwen (1972). Villus height, crypt depth and the numbers of goblet cells (no. per $100 \mathrm{~mm}$ crypt) were determined according to previously described procedures (Kik et al., 1990).

Analysis of variance (using treatment as a factor) were carried out with the software package of SPSS/PC+ V5.0 (SPSS, 1992). 


\section{RESULTS AND DISCUSSION}

Animals arrived at the Institute in good health. On day 6, one animal from the control group was euthanized because of very severe diarrhoea. Feed intake was similar $(\mathbf{P}>0.1)$ between groups. Average faecal consistency over the $13 \mathrm{~d}$ experimental period was 0.80 for the control and $0.61(\mathrm{P}<0.05)$ for the LP-s/LF group. For the major part of the experimental period the LP-s/LF group had a lower faecal consistency score than the control group. The differences were significant $(\mathrm{P}<0.05)$ at days 4,8 and 9 .

Results of the haematological examination determined at the end of the experiment showed that the numbers of basophils $(0.64 \%)$ were higher $(\mathrm{P}<0.05)$ in the control group compared to the LP-s/LF group $(0.07 \%)$. The numbers of eosinophils were increased $(\mathrm{P}<0.1)$ in the LP-s/LF $(0.00 \%)$ compared to the control group $(0.20 \%)$. There were no significant differences in haemoglobin, erythrocytes, haematocrit, leucocytes, neutrophils, lymphocytes and monocytes between the control and the LP-s/LF group.

The results of immunoglobins in blood serum are summarised in Table 1.

TABLE 1

Immunoglobulins in blood serum (SEM)

\begin{tabular}{lccc}
\hline & Control & LP-s/LF & Significance' \\
\hline IgG, g/l, day 2 & $8.57(1.23)$ & $5.33(1.18)$ & + \\
IgG, g/l, day I3 & $8.28(1.39)$ & $7.20(1.34)$ & NS \\
DIgG/Di, g/l/day & $-0.31(0.83)$ & $1.87(0.81)$ & + \\
\hline
\end{tabular}

'NS= difference is not significant $(\mathrm{P}>0.1)$

$*=$ difference is significant $(\mathrm{P}<0.05)$

$+=$ difference is significant $(\mathrm{P}<0.1)$

The IgG level of the LP-s/LF group was lower $(\mathrm{P}<0.1)$ than those of the control group on day 2. Overall, the IgG content of LP-s/LF group increased between days 2 and 13 whereas the content slightly decreased in the control group. The change in the IgG content (DIgG/Dt ( $\mathrm{g} / \mathrm{l}$ per day)) over the experimental period was different $(\mathrm{P}=0.1)$ between the groups. The lower IgG content at the start of the experiment suggests that the calves from the LP-s/LF group had a lower passive immunization than the control group. The increase in the IgG content of the LP-s/LF group during the experiment was probably related to an improved immune status. In the present experiment, no significant $(\mathrm{P}>0.1)$ correlation was found between IgG contents and the mean faeces score (not presented). The relation between IgG concentration and the occurrence of diarrhoea was studied by Rajala and Castren (1995). They concluded that IgG concentrations did not explain diarrhoea occur- 
TABLE 2

Microbiological parameters at different sites of the gastro-intestinal tract. SFM

\begin{tabular}{|c|c|c|c|}
\hline Site & Control & LP-s/LF & Significance \\
\hline \multicolumn{4}{|c|}{ Fresh samples facces, day 1 to 11} \\
\hline$\therefore$ Eccoli, $\log \mathrm{CFU}^{2}$ & $7.5(0.11)$ & $7.0(0.10)$ & * \\
\hline \multicolumn{4}{|c|}{ Jejunum, samples taken at dissection, day 14} \\
\hline- E.coli, $\log \mathrm{CFU}$ & $2.8(0.03)$ & $2.7(0.02)$ & NS \\
\hline$-\mathrm{LAB}^{3}, \log \mathrm{CFU}$ & $4.8(0.35)$ & $4.5(0.34)$ & NS \\
\hline \multicolumn{4}{|c|}{ Colon, samples taken at dissection, day 14} \\
\hline- E.coli, $\log \mathrm{CFU}$ & $5.3(0.44)$ & $4.2(0.48)$ & + \\
\hline$-\mathrm{LAB}, \log \mathrm{CFU}$ & $7.9(0.21)$ & $7.6(0.22)$ & NS \\
\hline
\end{tabular}

${ }^{1} \mathrm{NS}=$ difference is not significant $(\mathrm{P}>0.1)$

$*=$ difference is significant $(\mathrm{P}<0.05)$

$+=$ difference is significant $(\mathrm{P}<0.1)$

${ }^{2} \mathrm{CFU}=$ colony forming units

${ }^{3} \mathrm{LAB}=$ lactic acid producing bacteria

TABLE 3

Morphological and histometrical characteristics of the proximal jejunum $(0.75 \mathrm{~m}$ distal from the ligament of Treitz), mid jejunum ( $3 \mathrm{~m}$ distal from the ligament of Treitz) and distal jejunum $(0.5 \mathrm{~m}$ proximal of the ileo-caecal ligament) (SEM)

\begin{tabular}{|c|c|c|c|}
\hline Site & $\begin{array}{l}\text { Control } \\
(n=14)\end{array}$ & $\begin{array}{l}\text { LP-s/LF } \\
(n=15)\end{array}$ & Significance' \\
\hline \multicolumn{4}{|l|}{ Proximal jejunum } \\
\hline - villus shape scorc ${ }^{2}$ & $0.4(0.01)$ & $0.4(0.01)$ & NS \\
\hline \multicolumn{4}{|l|}{ Mid jejunum } \\
\hline - villus shape score ${ }^{2}$ & $0.3(0.07)$ & $0.2(0.07)$ & NS \\
\hline \multicolumn{4}{|l|}{ Distal jejunum } \\
\hline - villus shape score ${ }^{2}$ & $1.3(0.15)$ & $0.7(0.15)$ & * \\
\hline - villus height, mm & $229(1.3 .8)$ & $295(13.3)$ & $*$ \\
\hline - crypt depth, mm & $260(14.6)$ & $263(14.1)$ & NS \\
\hline - villus height/crypt depth & $0.91(0.62)$ & $1.15(0.60)$ & $*$ \\
\hline -- goblet cells, $\mathrm{n} / 100 \mathrm{~mm}$ crypt & $6.1(0.65)$ & $6.9(0.62)$ & NS \\
\hline
\end{tabular}

' $\mathrm{NS}=$ difference is not significant $(\mathrm{P}>0.05)$

$*$ difference is significant $(\mathrm{P}<0.05)$

${ }^{2}$ scale: 0 (ideal) to 3 (highly affected villi)

rence. In addition, the lower CFU of E. coli in the distal GI tract is a factor which can, secondarily, affect the immune status.

The CFU of $E$. coll in the colonic digesta and in the faeces of the control calves were higher than those of the $\mathrm{LP}-\mathrm{s} / \mathrm{LF}$ group $(\mathrm{P}=0.10$ and $\mathrm{P}<0.05$, respectively) 
(Table 2). There were no significant differences ( $\mathrm{P}>0-.1)$ in the CFU of $E$. coli in the digesta from the jejunum. These results are in accordance with Still et al. (1989) who showed an effect of a combination of LP-s and LF on the severity of diarrhoea in calves over the period 0 to 6 days after an experimental $E$. coli infection. They concluded that LP-s/LF had preventive and curative effects after the $E$. coli infection.

Counts of lactic acid producing bacteria (LAB) in the jejunum and colon were not significantly different $(\mathrm{P}>0.1)$ between the groups. The colonic contents of one animal of the control group were positive for salmonella whereas no salmonella positive animals were found in the LP-s/LF group.

Dissecting under the microscope, no differences in morphology of villus shape were found in the proximal or mid jejunum. However, in the distal jejunum, the villus shape scores were higher $(\mathrm{P}<0.05)$ in the $\mathrm{LP}-\mathrm{s} / \mathrm{LF}$ fed calves compared to those of the control group (Table 3 ). Histometrically, the mean villus height in the distal jejunum of the LP-s/LF group was also significantly higher $(\mathrm{P}<0.05)$ than that of the control group. There were, however, no differences in crypt depth or goblet cell density $(\mathrm{P}>0.1)$ between the groups.

In summary, in the present experiment LP-s/LF addition to milk replacer decreased the severity of diarrhoea and decreased the numbers of $E$. coli in faeces and colon of young calves. Morcover, a beneficial effect on the shape and height of the villi in the distal jejunum was observed in young calves fed a milk replacer diet supplemented with LP-s/LF.

\section{REFERENCES}

De Wit J.N., van Hooydonk A.C.M., 1996. Structure, functions and applications of lactoperoxidase in natural antimicrobial systems. Neth. Milk Dairy J. 50, 227-224

FNZ (Federatie Nederlandse Zuivelindustrie), 1986. 53.29. Present name: NZO (Nederlands Zuivel Organizatie), P.O. Box 165, 2700AD Zoetermeer, The Netherlands

IDF (International Dairy Federation), 1985. Standard 73A. IDF, 41, Square Vergrote, B-1030 Brussels, Belgium

IDF (International Dairy Federation), 1997. Standard 170, Part 3. IDF, Square Vergrote 41, B-1030 Brussels, Belgium

ISO (International Organization for Standardization), 1993. Publication 6579 . ISO, P.O.Box 5059, 2600 GB Delft, The Netherlands

Kik M.J.L., Huisman J., van der Poel A.F.B., Mouwen J.M.V.M., 1990. Pathologic changes of the small intestinal mucosa of pigs after feeding Phaseolus vulgaris beans. Vet. Pathol. 27, $329-334$

Lönnerdal B., Iyer S., 1995. Lactoferrin molecular structure and biological function. Ann. Rev. Nutr. 15, 93-110

Mouwen J.M.V.M., 1972. White scours in piglets at three weeks of age. PhD Thesis, University of Utrecht, The Netherlands 
Mouwen J.M.V.M., Egberts H.J.A., Koninkx J.F.J.G., 1983. The outermost mucosal barrier of the mammalian small intestine. Dte Tierärztl. Wochenschr. 90, 477-482

NEN (Nederland Normalisatie Instituut), 1994. Publication 6871. NEN, P.O. Box 5059, 2600 GB Delft. The Netherlands

Rajala P., Castren H., 1995. Serum immunoglobulins and health of dairy calves in two management systems from birth to 12 weeks of age. J. Dairy Sci. 78, 2737-2744

Reiter B., Perraudin J-P., 1991. Lactoperoxidase. Biological functions. In: J. Everse, K.F. Everse, M.B. Gruisham (Editors). Peroxidases in chemistry and biology Vol. 1. Boca Raton, FL, USA. C.R.C. Press Inc., pp. 143-180

SPSS (Statistical Package for Social Sciences)., 1992. Marija J. Norusis/SPSS Inc., SPSS/PC+ Version 5.0 Base. System User's Guide. SPSS, Chicago, IL, USA 